\title{
Research on the effectiveness of individual infiltration devices
}

\author{
Ewa Suchanek-Gabzdyl ${ }^{1, *}$, Maciej Mrowiec ${ }^{2}$ \\ ${ }^{1}$ University of Bielsko-Biala, Poland \\ ${ }^{2}$ Czestochowa University of Technology, Poland
}

\begin{abstract}
The increasing urbanization process in Europe has resulted in an increase in the proportion of impervious areas in the development of watersheds. This fact, combined with the more frequent occurrence of volatile rainfall, contributes to the formation of high intensity surface runoff, which results in local flooding of the lowest located areas. Water runoff also causes a large amount of pollution from the catchment to be flushed away and transported to the receiver, which generates many negative effects on the environment. Due to these unfavorable changes in the urban catchment, it is necessary to manage the waters in accordance with the principles of sustainable development. One of the basic tools to protect the quantity and quality of water discharged from the catchment area is to take into account the need to implement technical solutions to increase the retention of rainwater in cities. Such solutions, consisting of designing natural rainwater management systems, could work independently or in cooperation with traditional rainwater drainage systems [1].
\end{abstract}

\section{Research methodology}

The research included the analysis of a single object, i.e. a building with a specific roof surface, from which rainwater flows to the rainwater harvesting system or to the infiltration basin. The functioning of sewage infrastructure was not taken into account - only the balance of utility water consumption and water volume was carried out, which can be transferred via a storm overflow to the municipal drainage system.

Both precipitation models and data recorded on measuring devices were used in the research. Since no local precipitation models developed for Bielsko-Biała were found, the research used a model according to the Błaszczyk formula $(C=1$ year). Local rainfall data obtained from IMGW from Aleksandrowice Bielsko-Biała station was also used. In the first stage of the study, precipitation daily sums were used, recorded during the 22 years of observation (from 01/04/1993 to 31/10/2014), with the months April to October being taken into account. In the case of extreme events, a higher time resolution was used to determine the effectiveness of tanks for the economic use of rainwater in reducing runoff to the drainage system. As a criterion for the selection of extreme rainfall, the daily value of rainfall equal to or greater than $40 \mathrm{~mm}$ was assumed. During the 22 years, 45 events took place that met the

\footnotetext{
* Corresponding author: esuchanek@ath.bielsko.pl
} 
adopted criteria. Each of the selected rainfall events was presented in the form of hyetographs with a ten-minute step.

\subsection{The operation model of an individual micro retention system}

\subsubsection{The rainwater harvesting system}

For the first stage of the research, the model of a rainwater harvesting system (hereinafter referred to as RHS) was adopted, which includes the following elements: collection (roof area), storage (tank for the economic use of rainwater), and then the economic use of rainwater. The effectiveness of such a system depends on the following parameters: the amount of precipitation, the volume of the rainwater collection tank, the size of the roof surface, and the demand for usable water.

Each household may have a different number of inhabitants, the roof surface and the structure of water consumption, therefore the potential for using rainwater can be estimated based on two relative parameters [2]:

1. retention capacity $V_{w}$ :

$$
V_{W}=\frac{V}{F}[m m]
$$

where:

$V$ - total retention volume $\left[\mathrm{dm}^{3}\right]$,

$F$ - effective roof area $\left[\mathrm{m}^{2}\right]$.

2. water consumption $Z_{w}$ :

where:

$$
Z_{W}=\frac{Z}{F}[\mathrm{~mm}]
$$

$Z$ - 24 h water consumption $\left[\mathrm{dm}^{3} / \mathrm{d}\right]$,

$F$ - effective roof area $\left[\mathrm{m}^{2}\right]$.

The efficiency of RHS tanks was defined as the degree of coverage of the demand for drinking water by the use of rainwater and calculated on the basis of the formula:

$$
E_{W}=\frac{\Sigma V_{d}}{\Sigma V_{z}} \cdot 100 \%[\%]
$$

where:

$\Sigma V_{d}$ - the sum of the rainwater heights used for economic purposes [mm],

$\Sigma V_{Z}$ - the sum of the useful water height used in the considered period [mm].

The calculations made for the period of 22 years also made it possible to determine the height of $h_{o}[\mathrm{~mm}]$ discharges by the storm overflow of the micro retention devices into the sewage system. The height of the discharges was related to the total amount of rainfall, which was recorded in the analyzed period for different values of the relative amount of daily usable $h_{z w}$ water consumption and the relative retention altitude $h_{v r}$ :

$$
\mathrm{o}_{\mathrm{W}}=\frac{\Sigma \mathrm{V}_{\mathrm{ov}}}{\Sigma \mathrm{V}_{\mathrm{op}}} \cdot 100 \%[\%]
$$

where: 
$\Sigma V_{o v}$ - the sum of the height of rainwater discharged into the sewage system by the storm overflow of the reservoir / basin [mm],

$\Sigma V_{o p}$ - total height of rainwater discharged into the sewage system in the absence of micro retention devices $[\mathrm{mm}]$.

For the 45 selected rainfall events, the daily height of which exceeded $40 \mathrm{~mm}, 10$-minute hyetographs were available, thanks to which a detailed analysis of the functioning of micro retention devices was possible. The analysis concerned mainly the assessment of the outflow limitation in the range of instantaneous rainfall exceeding the values accepted for the design of storm overflow - according to the literature, the range of values ranges from $6 \mathrm{dm}^{3} / \mathrm{s} \cdot$ ha to $15 \mathrm{dm}^{3} / \mathrm{s} \cdot$ ha.

\subsubsection{Infiltration basins}

In the calculations, a rainwater retention and infiltration model was adopted, which includes the following elements: collection (roof surface), storage (infiltration basin) and rainwater drainage (infiltration to the ground). The method of its operation is determined, inter alia, by: the amount of atmospheric precipitation, the volume of the infiltration basin, the size of the roof surface, and the water permeability of the ground. In the case of the infiltration basin model, the following assumptions were made: the maximum filling of the basin is $0,25 \mathrm{~m}$, and the ratio of the infiltration area to the dehydrated surface is in the $f_{\text {INF }}$ range $=0,05 \div 0,15$.

In the research on infiltration devices, it is important to take into account the different values of the water permeability coefficient (infiltration) of the $k_{f}$ soil. The $k_{f}$ coefficient used in the calculations is very diverse on land. The following values of the coefficient $k_{f}$ were adopted: $10^{-4}[\mathrm{~m} / \mathrm{s}], 5 \cdot 10^{-5}[\mathrm{~m} / \mathrm{s}], 10^{-5}[\mathrm{~m} / \mathrm{s}], 10^{-6}[\mathrm{~m} / \mathrm{s}]$.

The calculation of the total amount of overflows through the storm overflow of the device was made using the formula 4.

\section{Studies on the impact of the use of rainwater harvesting systems on the relief of combined sewerage}

\subsection{Analysis for daily data}

The graph (Fig. 1) presents the results of the simulations carried out for the assumed range of values of the parameters of daily use water consumption and the retention height $h_{v r}$. Taking into account the potential benefits for the system user, the range of $h_{v r} \in[20 \div 30 \mathrm{~mm}]$ seems to be the best choice. A significant increase in the retention height does not translate into a proportional increase in the coverage of the usable water demand. 


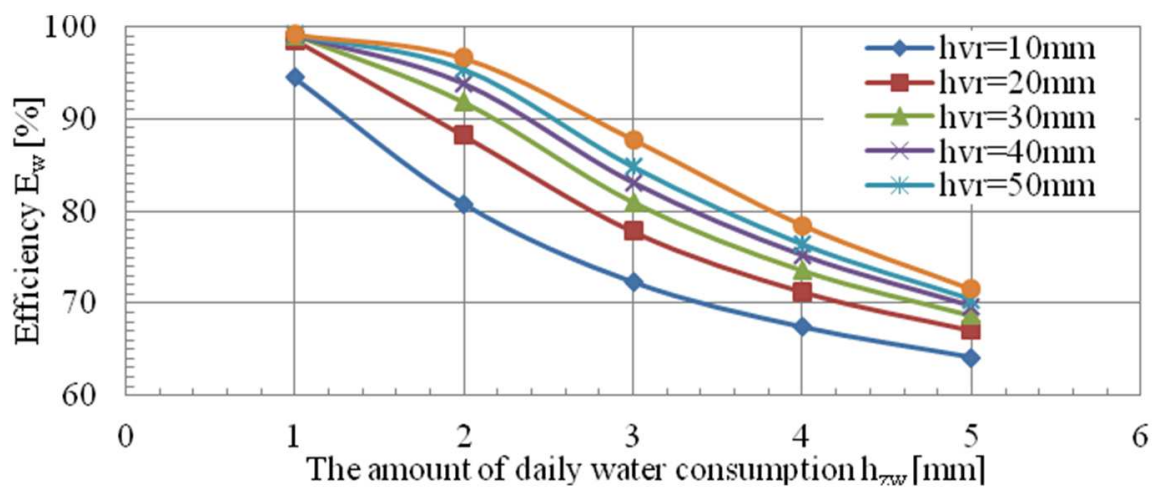

Fig. 1. Effectiveness of rainwater utilization depending on the amount of daily water consumption $h_{z w}$ and the retention height $h_{v r}$.

The graph (Fig. 2) shows the results of analyses in relation to the volume of discharges via the emergency overflow depending on $h_{z w}$ and $h_{v r}$. The graph shows the percentage of year-round precipitation going into the sewer for the variable parameter values $(100 \%$ means the volume of discharges in the absence of any retention). Considering the use of RHS tanks for economic needs, it can be concluded that a reservoir with a small retention height $\left(h_{v r}\right.$ in the range of $10 \div 20 \mathrm{~mm}$ ) is sufficient. However, if the tank is used additionally to relieve the sewerage network, the total retention height should be in the range from $30 \mathrm{~mm}$ to even 50 $\mathrm{mm}$.

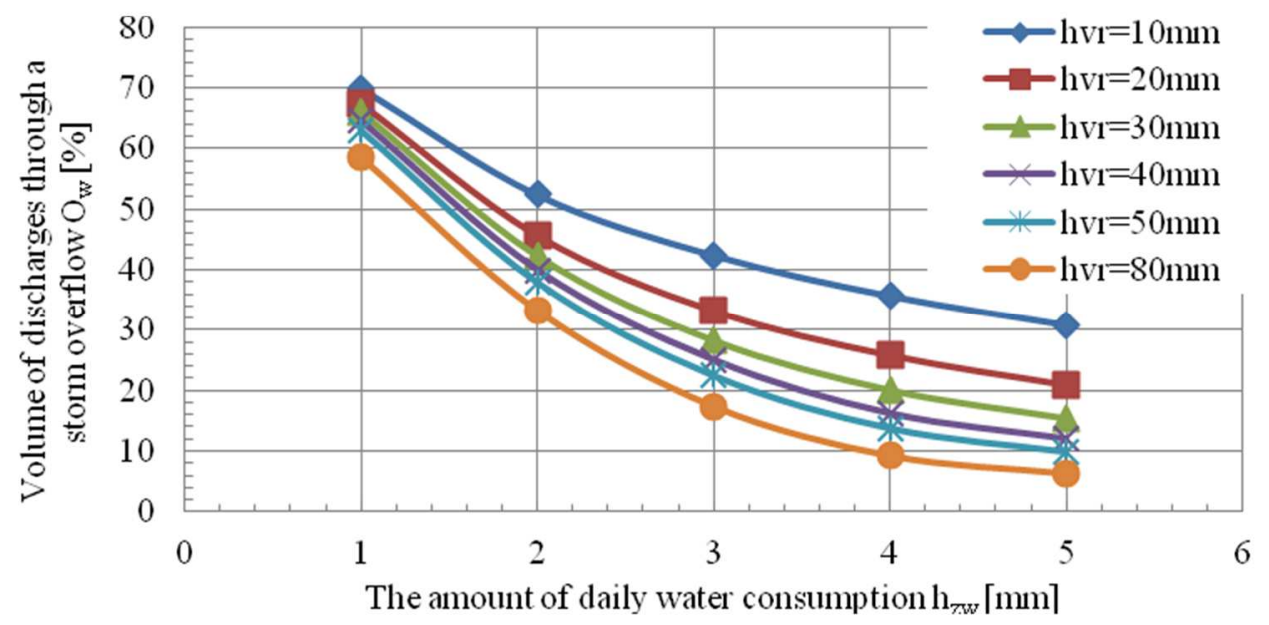

Fig. 2. The volume of discharges by the storm overflow depending on daily water consumption $h_{z w}$ and the retention height $h_{v r}$.

\subsection{Analysis for selected precipitation events}

An analysis of the daily rain data provides knowledge on the average system efficiency, based on the data of low time resolution. For this reason, in the second stage hyetographs from 45 rainfall events recorded in 10-minute time intervals were used. When assessing the effect of the retention of RHS tanks on the possibility of reducing the volume of discharges by the storm overflow, a limit value of precipitation intensity $\left(q_{g r}\right)$ of $15 \mathrm{dm}^{3} / \mathrm{s}$ - ha was assumed as the one at which the storm overflow is not yet triggered. This is the amount of rain used, 
among others, in the design of rainwater sewage treatment equipment from a rainwater sewage system (a stream of sewage of greater intensity can be drained directly to the receiver). The rainfall rate of $15 \mathrm{dm}^{3} / \mathrm{s}$ - ha corresponds to a rainfall of $0,9 \mathrm{~mm}$ in 10 minutes.

The research results were referenced to the reference variant, i.e. without a RHS tank ( $h_{v r}=0 \mathrm{~mm}$ - no retention). Depending on the time variability and the amount of particular precipitation, the obtained results were very diverse. The graph (Fig. 3) illustrates the distribution of the value of the parameter ho (the height of sewage discharge to the receiver above $q_{g r}$ ) in the studied population of the 45 events. On this basis, the influence of the retention value on the ho parameter was determined. The use of retention height $\mathrm{h}_{\mathrm{vr}}=50 \mathrm{~mm}$ results in an almost complete reduction of $h_{o}$.

After calculating the percentage reduction of ho for each of the 45 rainfall events, the mean and median of the reduction for the variable values of the retention altitude $h_{\mathrm{vr}}$ were determined. In practice, this means that in an example roof with an area of $100 \mathrm{~m}^{2}, 2 \mathrm{~m}^{3}$ of the retention volume allows you to reduce the height of the ho, on average, by half. Increasing the retention height to $50 \mathrm{~mm}$, the average reduction in the height of $h_{o}$ is $90 \%$ and the median is already $100 \%$, which means that for more than half of the events it was possible to completely eliminate the discharge by the storm overflow.

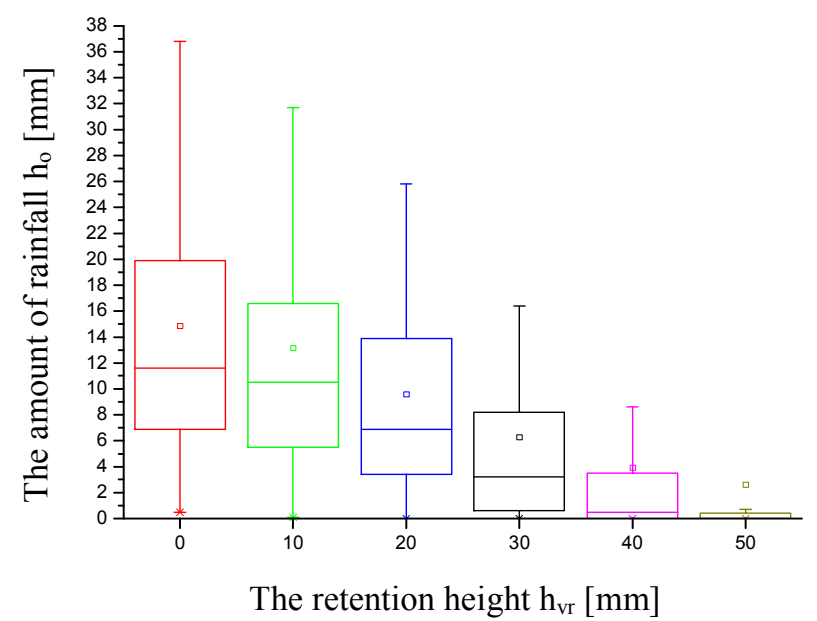

Fig. 3. The value of the $h_{o}$ parameter for the variable value of the retention altitude $h_{v r}$.

The graph (Fig. 4) shows a graph of the relationship between the daily amount of precipitation $\mathrm{h}$ and the discharge height $h_{o}$. In the variant without retention $\left(h_{v r}=0 \mathrm{~mm}\right)$, there is no clear correlation between these two values. If an increased retention level is used $\left(h_{v r}=40 \mathrm{~mm}\right)$, a clear linear relationship can be determined with a correlation coefficient $\mathrm{R}^{2}$ $=0,8613$ for $40 \mathrm{~mm}$ for $h_{v r}=50 \mathrm{~mm} \mathrm{R} \mathrm{R}^{2}=0,9427$. The occurrence of a linear correlation between the daily amount of rainfall and the $h_{o}$ value transfers the information value, which allows estimating the outflow above the $q_{g r}$ value for the expected daily rainfall. In systems equipped with real-time control modules, it is possible to effectively manage the retention capacity of tanks located in the sewerage network. 


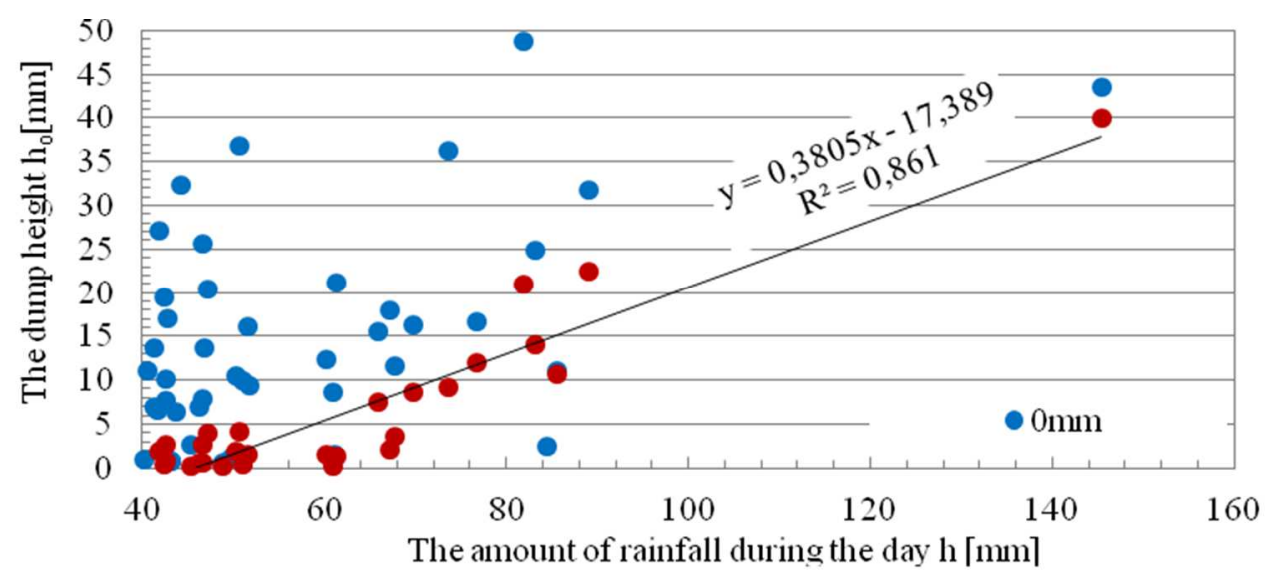

Fig. 4. The relationship between rainfall day height $h$ and discharge height $h_{o}$ for retention $h_{v r}=40 \mathrm{~mm}$

The use of retention not only reduces the volume of water that can enter the sewerage system, but primarily reduces the amount of rainfall that can cause the activation of a storm overflow. The analyses carried out concerned one object and could not be directly applied to the whole catchment. This is due to the fact that in real conditions only a part of the buildings will be equipped with installations for rainwater harvesting systems. It should also be noted that roofs are a fragment of all impervious surfaces in the whole catchment.

\section{Research on the impact of the use of infiltration basins on the relief of combined sewerage}

\subsection{Analysis of daily data}

For the period considered, the volume of discharges through the storm overflow was calculated depending on the water permeability coefficient $k_{f}$ and the relative infiltration surface $f_{I N F}$.

The analysis takes into account different values of the filtration coefficient (water permeability) from $10^{-4} \mathrm{~m} / \mathrm{s}$ to $10^{-6} \mathrm{~m} / \mathrm{s}$, while the relative infiltration area from $2,5 \%$ to $15 \%$. The results of the analyses (Fig. 5) indicate a much higher efficiency of infiltration pits in comparison to RHS tanks, for which a reduction of the volume of discharges up to $10 \%$ was possible at a reservoir with a retention height of $50 \mathrm{~mm}$ and high usage water values. Differences in the obtained results are a consequence of a different mode of operation of infiltration devices, which are emptied continuously and are independent of the daily water consumption characteristics. Irrespective of this, the obtained results seemed not fully reliable, taking into account the occurrence of several rainfall events with a height of over 60 $\mathrm{mm}$.

The main source of uncertainty of the obtained results is the time resolution of the precipitation data used. On a daily basis, the amount of water infiltrating the ground exceeds the highest recorded rainfall levels, which means that there is no overflow of infiltration devices at averaged daily outflow. Considering rainfall with a smaller time step, it is possible to take into account temporary extreme intensities, which will exceed the retention capacity of infiltration basins. 


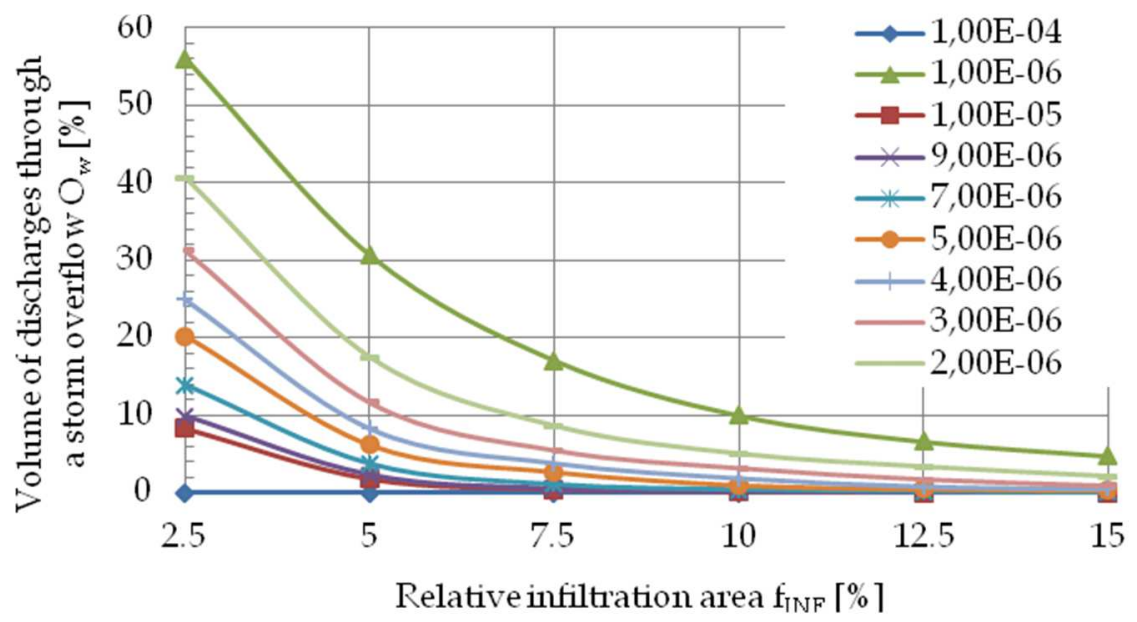

Fig. 5. Percentage of year-round rainfall going into the sewer for the variable values of $k_{f}$ and $f_{I N F}$.

\subsection{Analysis for the selected precipitation events}

In order to check the effect of daily diurnal resolution applied to the results of overflow calculations, additional calculations were made for the 45 rain events, whose histograms were recorded with a 10-minute time step. The diagrams (Fig. 6 and Fig. 7) show the results of analyses showing the consistency of calculations of the number of transfers using daily and 10-minute data.

In the case of unfavorable hydrogeological conditions $\left(k_{f}=10^{-6} \mathrm{~m} / \mathrm{s}\right)$ and the surface $f_{I N F}=5 \%$, a very good agreement of results was obtained for the given rainfall data with different time resolution - correlation coefficient $\mathrm{R}^{2}=0,999$. This means that with reduced flow through infiltration, it is prudent to use daily data.

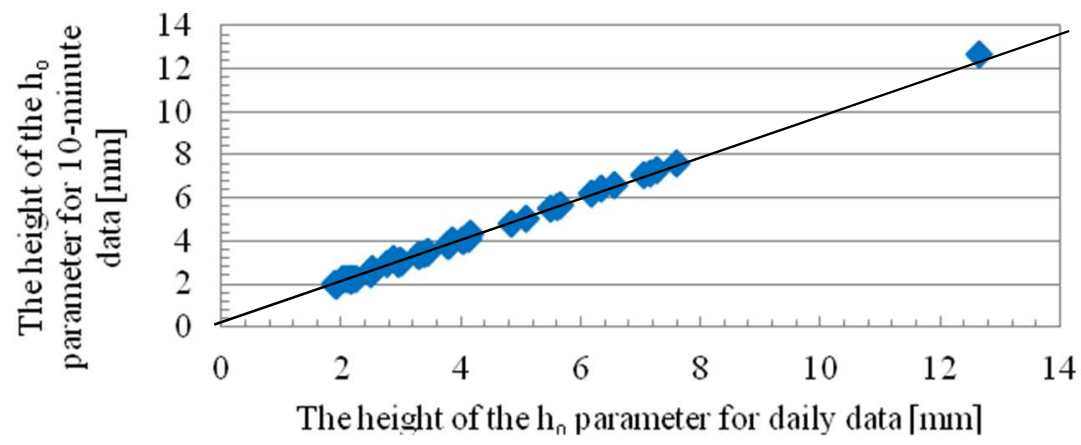

Fig. 6. Conformity between overflows via daily and 10 minutes storm overflow for $k_{f}=10^{-6} \mathrm{~m} / \mathrm{s}$ at $f_{I N F}=5 \%$.

Differing results were obtained for the coefficient $k_{f}=5 \cdot 10^{-5} \mathrm{~m} / \mathrm{s}$ at $f_{I N F}=10 \%$ - the consistency of the results is much worse and it can be clearly seen that the greatest discrepancies occur at low discharges heights. In this case, the use of daily data leads to an underestimation of the volume of discharges by a transfer to the sewerage network. As a result, the overflow calculations are underestimated. 


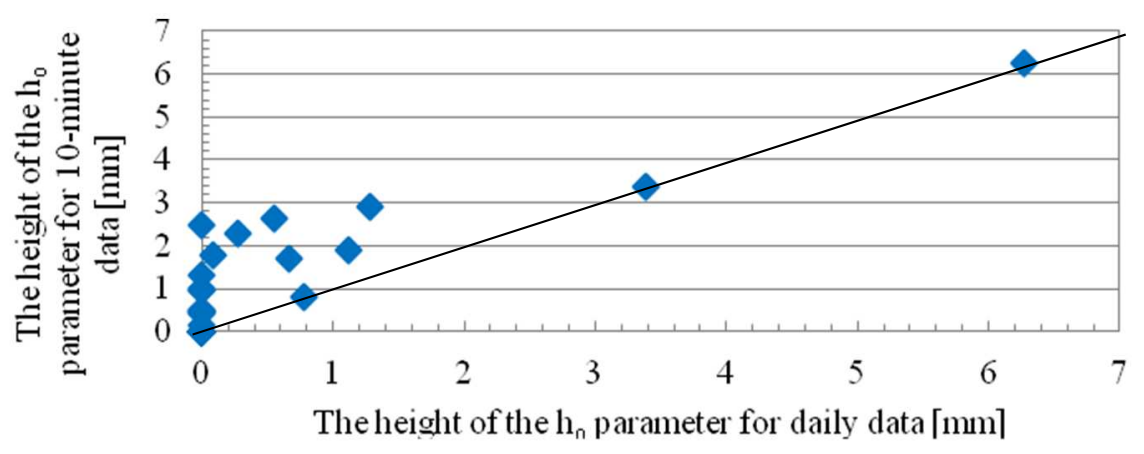

Fig. 7. Conformity between overflows via storm overflow daily and 10 minutes for $k_{f}=5 \cdot 10^{-5} \mathrm{~m} / \mathrm{s}$ at $f_{I N F}=10 \%$.

The graph (Fig. 8) presents the statistics of the number of overflows $\left(h_{o}>0 \mathrm{~mm}\right)$ for all the considered variants. In the case of $k_{f}=10^{-6} \mathrm{~m} / \mathrm{s}$ in none of the variants was it possible to reduce the number of events by more than $30 \%$. With the increase of the coefficient value, the number of events for which $h_{o}>0 \mathrm{~mm}$ is significantly reduced.

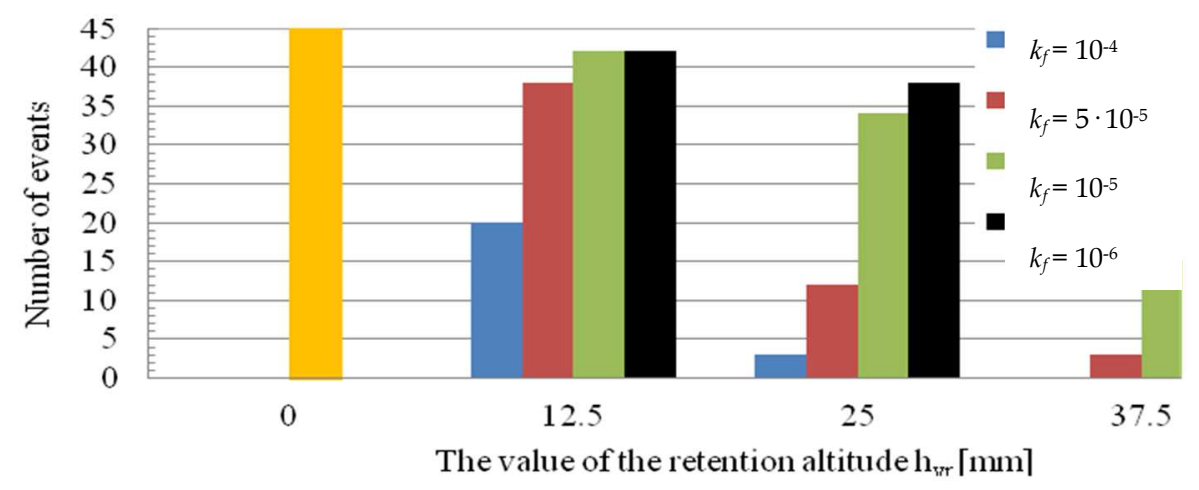

Fig. 8. Reduction of the number of rainfall events for which $h_{o}>0 \mathrm{~mm}$.

\section{Summary}

The use of micro retention devices in sewage systems is part of the concept of sustainable development of water and sewage management in urban areas. The conducted research and analysis enabled the quantification of potential benefits resulting from the application of microretention. Positive effects can be observed not only in the reduction of volume of discharges by storm overflows to receivers but also in increasing the hydraulic reliability of the combined sewer system.

\section{References}

1. A. Januchta-Szostak, Miasto w symbiozie z wodą, 14, rok 107 (2010)

2. A. Fewkes, Urban water, Modelling the performance of rainwater collection systems: towards a generalised approach Urban Water, 1, 323-333 (2000)

3. W. Geiger, H. Dreiseitl, Nowe sposoby odprowadzania wód deszczowych (1999) 